Brazilian Journal

of Chemical

\title{
CHANGES IN MECHANICAL PROPERTIES DUE TO GAMMA IRRADIATION OF HIGH-DENSITY POLYETHYLENE (HDPE)
}

\author{
S. S. Cota ${ }^{*}$, V. Vasconcelos, M. Senne Jr., L. L. Carvalho, \\ D. B. Rezende and R. F. Côrrea \\ Centro de Desenvolvimento da Tecnologia Nuclear, CDTN/CNEN, \\ Phone: +(55) (31) 3069-3418, Fax: +(55) (31) 3069-3257, Cx P 941, \\ CEP 30123-970, Belo Horizonte - MG, Brazil. \\ E-mail: sdsc@cdtn.br
}

(Received: March 8, 2006 ; Accepted: February 22, 2007)

\begin{abstract}
This paper presents an experimental analysis of the effect of dose and dose rate parameters during gamma irradiation of high-density polyethylene (HDPE) samples. Considerations concerning the influence of these parameters on HDPE mechanical strength properties as a result of the predominance of oxidative degradation or of cross-linking are presented. The experimental results show an improvement of HDPE mechanical strength as dose increases, indicating the predominance of cross-linking over oxidative degradation and that lower doses are necessary to obtain a similar change in resistance parameters when radiation is applied at lower dose rates, showing that gamma radiation affects the HDPE in a more efficient way at lower dose rates.

Keywords: Gamma irradiation; Polymers; Mechanical properties.
\end{abstract}

\section{INTRODUCTION}

The effects of radiation on polymer structure, and consequently on its physical characteristics, are well known in the plastics industry. The literature on the mechanisms behind these effects shows two opposite trends, depending on irradiation conditions: crosslinking of the polymer molecules, which increases the mechanical strength and oxidative degradation, which generally causes material weakening. Which tendency will be predominant seems to be related to the amount of oxygen available on the material and the capability to replace the oxygen as it is consumed by chemical reactions with radicals produced during irradiation.

A discussion of the effect of radiation on mechanical strength as a consequence of the balance between cross-linking and oxidative degradation is presented in many publications. Wündrich (1985) presents a review of the literature on values for mechanical resistance parameters for several plastics and elastomers submitted to radiation under different conditions. Instead of directly presenting the parameter values, the radiation effects were compared using the half-dose value concept, defined as the absorbed dose necessary to reduce the parameter value to $50 \%$ of the initial value. According to the author, increases in parameter values were observed, mainly in cases involving high doses, but these effects were not relevant in practical terms.

An analysis of the above-mentioned data shows that, when irradiation is carried out in the absence of oxygen (vacuum or inert atmosphere), the effect of radiation on the mechanical resistance parameters is independent of dose rate. On the other hand, in the

*To whom correspondence should be addressed 
presence of air, the relationship between effect and dose rate is evident. For example, for high-density polyethylene, the half-dose value for ultimate tensile stress is reduced gradually with the reduction in dose rate. In the absence of air, this dose is larger than the values for irradiation in the presence of air. Wündrich attributes this behavior to the influence of oxygen in the degradation of polymers (oxidative degradation). This effect increases with the reduction in dose rate because it is a time-related process due to two mechanisms: the diffusion of oxygen in the polymer and the disintegration reaction of the peroxides formed.

Singh (1999) presents mechanisms that corroborate these comments. According to the author, two phenomena occur as a consequence of the HDPE gamma irradiation process: the formation of cross-linking and oxidative degradation. In general, Eq. (1) shows the reaction between free radicals (PE $\bullet$ ) of HDPE, produced by the loss of a hydrogen atom of HDPE (represented as PE), forming cross-linking between polymer molecules. This recombination reaction is predominant in cases of irradiation in vacuum or inert atmospheres.

$\mathrm{PE} \bullet+\mathrm{PE} \bullet \rightarrow \mathrm{PE}-\mathrm{PE}$

During irradiation in the presence of air, the formation of peroxide radical (Eq. (2)) and the reaction of the $\mathrm{PE}$ free radical and the peroxide radical (Eq. (3)) predominates.

$$
\begin{aligned}
& \mathrm{PE} \bullet+\mathrm{O}_{2} \rightarrow \mathrm{PEO}_{2} \bullet \\
& \mathrm{PE} \bullet+\mathrm{PEO}_{2} \bullet \rightarrow \mathrm{PEOOPE}
\end{aligned}
$$

Singh (1999) also discusses that at very high dose rates $\left(10^{3} \mathrm{~Gy} / \mathrm{s}\right.$, generated in electron accelerators), the formation of cross-linking (Eq. (1)) is the predominant reaction. This happens because the oxygen is quickly consumed and the formation of peroxide radical (Eq. (2)) becomes limited to the oxygen diffusion rate.

The complexity of the phenomena resulting from HDPE irradiation is also discussed by Premnath et al. (1999). According to the authors, specific effects of polyethylene irradiation may differ depending on factors such as polymer molecular weight; the presence of additives; temperature; storage under atmospheric conditions before, during and after irradiation; and size of the samples, among others.

Premnath et al. (1999) present an evaluation of effects at the molecular level during storage of irradiated ultra-high molecular weight polyethylene in air for long periods of time. The thickness of the samples and the time of irradiation were chosen to eliminate the effect of oxidation during irradiation and to allow oxygen renewal throughout the sample during storage. The irradiation was carried out with $2.5 \mathrm{MeV}$ electrons and at a dose rate of $20 \mathrm{kGy} / \mathrm{min}$ for different doses. Parameters related to crystallinity, degree of oxidation and presence of free radicals were determined for the samples after irradiation and for different storage times.

After irradiation, for doses of 10 to $200 \mathrm{kGy}$, the formation of cross-linking exceeded the effect of oxidative degradation and the degree of cross-linking increased with the increase in absorbed dose. During the after-irradiation storage time (up to 29 months), a significant increase in oxidation rate and the formation of small chains were observed. The degree of oxidation increased almost linearly with dose during storage time, but the incremental oxidation was larger at the beginning of storage time. This effect was related to the number of free radicals formed during irradiation, which was linearly related to the adsorbed dose, but was also limited by the oxidation kinetics for longer times, due to the diffusion of the oxygen and free radicals in the samples. The experiment also showed that the alkyl radicals $\left(-\mathrm{CH}_{2} \mathrm{CH}-\mathrm{CH}_{2}-\right)$ disappeared from the system 48 hours after the end of irradiation, but that the peroxide radical $\left(-\mathrm{CH}_{2}-\mathrm{COOH}-\mathrm{CH}_{2}-\right)$ survived for at least 30 months.

In his analysis of the effectiveness of gamma radiation to reduce the wear resistance of polyethylene orthopedic implants, McKellop (1996) asserts that polyethylene irradiation results in the scission of polymeric chains and the formation of free radicals. In the presence of air, either incorporated into the material during manufacture or later by diffusion, the oxygen can react with the free radicals, reducing the polymer molecular weight, resulting in a more brittle material, and reducing the fracture resistance and the ultimate elongation. Moreover, oxidation of the samples can continue with time, due to the presence of long-life radicals, reaching a maximum on 0.5 to 2.0 $\mathrm{mm}$ below the polymer surface.

However, the author comments that, in the absence of air during irradiation, the free radicals tended to form bonds with adjacent molecules, resulting in an increase in wear resistance. Oxidation and cross-linking are competing phenomena, and maximum oxidation occurs on the surface of the material, decreasing with depth. So the number of cross-linkings should be at a minimum on the surface and at a maximum at the center of the sample. 
According to Martins et al. (1999), gamma irradiation of polyethylene in air at doses of 10 to $2000 \mathrm{kGy}$ and a dose rate of $2.5 \mathrm{kGh} / \mathrm{h}$ improved the mechanical resistance parameters as the adsorbed dose was increased. In the tensile tests, an increase in ultimate tensile stress and a reduction in the ultimate elongation were observed, while in the compression tests an increase in yield stress and a $50 \%$ offset yield stress were observed.

In general the literature shows a clear relationship between the absorbed dose and the parameters of mechanical resistance of polymers. However, the tendency of this relationship cannot be easily determined. The different conclusions about the effect of radiation on polymers, observed in the papers analyzed, can be related to the fact that mechanical resistance is a macroscopic effect of multiple phenomena that occur on a microscopic scale. In other words, the formation of cross-linking and oxidative degradation seem to occur simultaneously and in a nonhomogeneous way across the sample, while the mechanical resistance parameters show the results of integration of these phenomena across the sample. McKellop (1996) pointed out an example of this fact that links the predominance of oxidation with the real availability of oxygen to react with the free radicals. During irradiation in the presence of air, oxygen renewal across the sample depends on its dimensions.

Moreover, only Wündrich (1985) included a discussion about the relationship of mechanical strength with dose rate; the papers on this issue usually just addressed the variation with absorbed dose. The influence of dose rate on mechanical parameters pointed to in this work shows a greater predominance of oxidation in air irradiation, which is accentuated by a reduction in dose rate. However, the effects of irradiation in the presence of air depend on other factors, such as sample dimensions, and the conclusions about these effects can not be properly addressed without considering the influence of these factors.

Concerning the influence of dose rate on irradiation tests in polymer materials, the CEI/IEC 544-2: 1994 International Standard "Guide for determining the effects of ionizing radiation on insulating materials" recommends use of a dose rate higher than $3600 \mathrm{~Gy} / \mathrm{h}$ for a short exposure under nonoxidizing conditions (absence of oxygen or thick samples) and up to $108 \mathrm{~Gy} / \mathrm{h}$ for a long exposure in the presence of air. Here, these two conditions provide a measure of the time-related effects of oxygen. The first condition seems to increase the formation of cross-linking by minimizing irradiation time and oxygen availability, while the second one allows oxidation of the polymer.

Based on these literature review conclusions, experiments were designed in order to study the influence of gamma irradiation dose and dose rates on mechanical strength parameters. This paper presents experimental results of the irradiation in air with a Cobalt-60 gamma source of high-density polyethylene (HDPE) samples to address the radiation effect on compression and tensile parameters. These parameters were evaluated for three levels of dose rates and five levels of absorbed dose.

\section{METHODOLOGY}

A commercial-grade plate of high-density polyethylene (HDPE) with a density of $0.950 \mathrm{~g} / \mathrm{cm}^{3}$ and a thickness of $12.5 \mathrm{~mm}$ was used to produce the samples for the irradiation experiments. For the compression tests, $12.5 \times 12.5 \times 25.4 \mathrm{~mm}$ prismatic samples were prepared according to ASTM standard D 695-91. For the tensile tests, the samples were cut at a thickness of $12.5 \mathrm{~mm}$ (Type III) in accordance with ASTM standard D 638-91. Both mechanical strength tests were carried out on an Instron universal testing machine, model TTDML, applying all the requirements of ASTM standard D 695-91 for the compressive tests and ASTM standard D 638-91 for the tensile tests, with the exception of the temperature and humidity control. All tests were carried out at room temperature.

The gamma irradiation process was carried out in the Laboratório de Irradiação Gama (LIG) at CDTN, which is equipped with a GB-127 Irradiator from MDS Nordion. This equipment operates with Co-60 sources with a total activity of $60 \mathrm{kCi}$. The irradiation chamber as well as the complementary systems was designed to guarantee the dose homogeneity of the irradiated items. The dosimetry inside the irradiation chamber is based on the dose rate mapping generated during irradiator installation and is constantly updated due to radioactive decay. Irradiation of the samples was conducted at room temperature and in the presence of air.

According to the ASTM standards D 695-91 and D 638-91, five samples were required for each determination of mechanical strength. Therefore, fifteen sets of samples, each one composed of five tensile strength test samples and five compressive strength test samples, were exposed inside the irradiation chamber to three dose rates and five dose levels, as described in Table 1. 
Table 1: Doses and dose rates applied during the irradiation experiments.

\begin{tabular}{|c|c|c|c|}
\hline Dose levels & $\mathbf{1 1 5} \mathbf{~ G y} / \mathbf{h}$ & $\mathbf{5 0 0} \mathbf{~ G y} / \mathbf{h}$ & $\mathbf{1 0 0 0} \mathbf{G y} / \mathbf{h}$ \\
\hline 1 & $80 \mathrm{kGy}$ & $360 \mathrm{kGy}$ & $720 \mathrm{kGy}$ \\
2 & $70 \mathrm{kGy}$ & $250 \mathrm{kGy}$ & $500 \mathrm{kGy}$ \\
3 & $50 \mathrm{kGy}$ & $150 \mathrm{kGy}$ & $250 \mathrm{kGy}$ \\
4 & $30 \mathrm{kGy}$ & $80 \mathrm{kGy}$ & $150 \mathrm{kGy}$ \\
5 & $20 \mathrm{kGy}$ & $50 \mathrm{kGy}$ & $80 \mathrm{kGy}$ \\
\hline
\end{tabular}

Each sample set was removed from the irradiator chamber after the exposure time necessary to obtain each one of the absorbed integrated doses shown in Table 1. After the end of the irradiation process, the samples were placed in plastic bags and degassed in vacuum and the bags were sealed to avoid contact with air. The samples were submitted to the mechanical resistance tests as quickly as possible in order to minimize the effects of postirradiation oxidation.

\section{RESULTS AND DISCUSSION}

Figures 1 to 5 show the mechanical strength parameter values obtained from compression and tensile tests for each dose rate and different adsorbed doses. The values of $5 \%$ offset yield stress (Figure 1) and yield stress (Figure 2) for compression tests increased as absorbed dose increased. For example, for a dose of $720 \mathrm{kGy}$ and a dose rate of $1000 \mathrm{~Gy} / \mathrm{h}$, the percent increase in the mean values of the irradiated samples over the nonirradiated ones were 22.7 and $29.9 \%$ for $5 \%$ offset yield stress and yield stress, respectively. In the case of modulus of elasticity from compression tests (Figure 3), most of the measured data are above the measured value for the nonirradiated sample. However, the large spread of the measured values makes it difficult to analyze the tendencies.

An analysis of Figures 1 and 2 shows that the offset yield stress for compression tests was apparently more influenced by irradiation at lower dose rates. These figures show that the same increase in stress was obtained with lower doses when irradiation was carried out at lower dose rates. Doing a regression analysis of the $5 \%$ offset yield stress data related to each dose rate, it is possible to verify that a dose increment of $196 \mathrm{kGy}$ was necessary to cause a unit increment of this parameter when a dose rate of $1000 \mathrm{~Gy} / \mathrm{h}$ was applied (the parameter increased from 29 to 30 $\mathrm{MPa}$ ). This dose increment was be $87 \mathrm{kGy}$ at a dose rate of $500 \mathrm{~Gy} / \mathrm{h}$ (from 29 to $30 \mathrm{MPa}$ ) and $25 \mathrm{kGy}$ at a dose rate of $115 \mathrm{~Gy} / \mathrm{h}$ (from 27 to $28 \mathrm{MPa}$ ), which indicates the tendency of the mentioned parameter to increase more efficiently at lower dose rates than at higher ones.

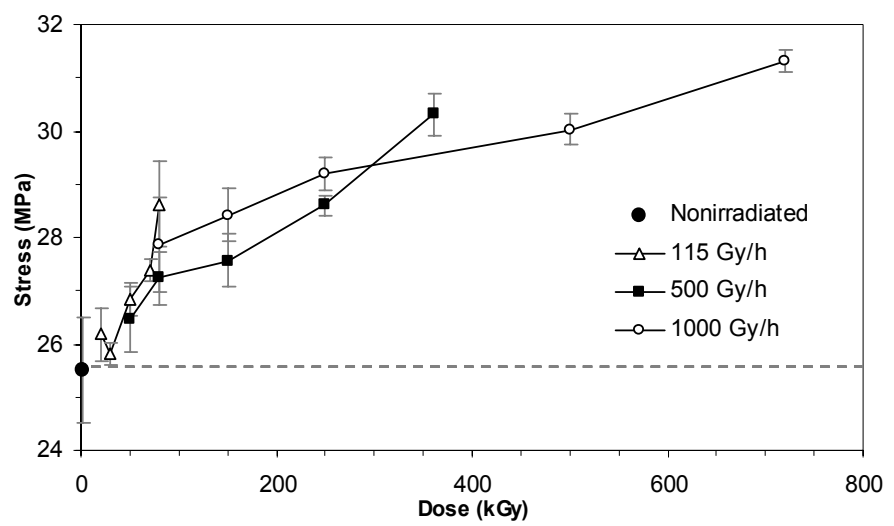

Figure 1: $5 \%$ offset yield stress of irradiated samples from compression tests as a function of dose and dose rate. Error bars indicate the $95 \%$ confidence interval. 


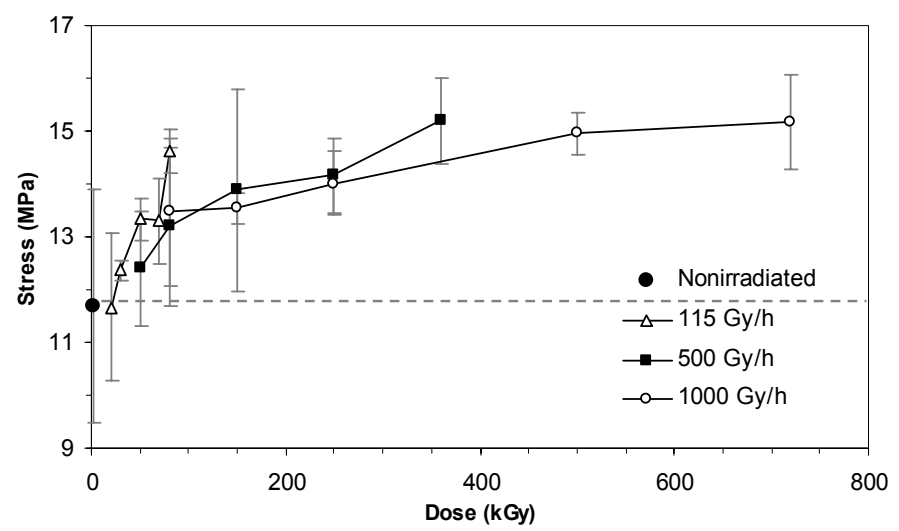

Figure 2: Yield stress of irradiated samples from compression tests as a function of dose and dose rate. Error bars indicate the $95 \%$ confidence interval.

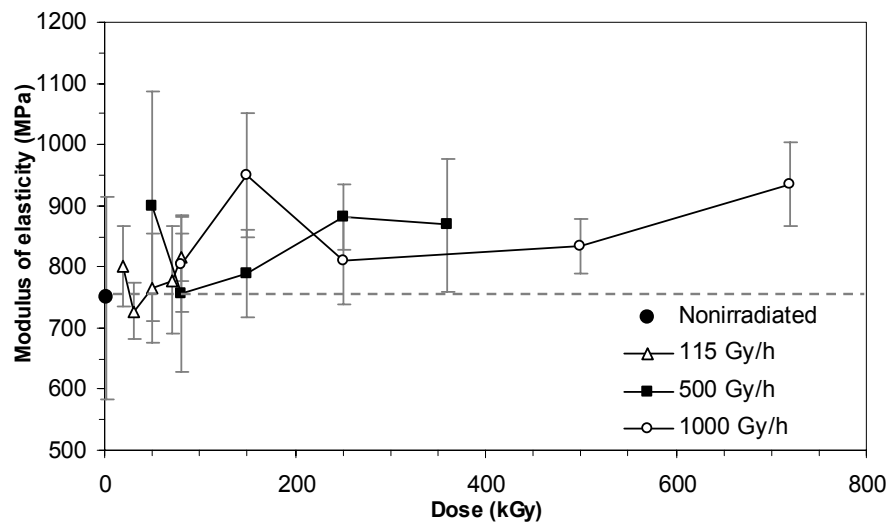

Figure 3: Modulus of elasticity of irradiated samples from compression tests as a function of dose and dose rate. Error bars indicate the $95 \%$ confidence interval.

At a $115 \mathrm{~Gy} / \mathrm{h}$ dose rate, analysis of the parameters obtained by the tensile tests shows a reduction in the percent increase in mean values of yield stress (Figure 4) of the irradiated samples over the nonirradiated ones as dose increased. For higher dose rates, however, the progressive tendency of this parameter to decrease observed at lower doses was replaced by an also progressive tendency to increase. The lowest yield stress value reached in this process increased with the dose rate. A possible explanation for this behavior could be that, at lower dose rates, oxidative degradation was predominant due to the slower consumption of the oxygen present in the samples. As dose rate increased, the oxygen was more rapidly consumed, and after the oxygen in the sample was used up, the free radicals formed by irradiation began to improve cross-linking between PE molecules.

The modulus of elasticity (Figure 5) was found to decrease over all dose and dose rate intervals. This tendency increased as the absorbed dose increased, reaching a $46.3 \%$ reduction over values measured for nonirradiated samples for an $80 \mathrm{kGy}$ dose at a 115 $\mathrm{Gy} / \mathrm{h}$ dose rate; $32.3 \%$, for a $360 \mathrm{kGy}$ dose at 500
$\mathrm{Gy} / \mathrm{h}$; and $53.1 \%$, for a $720 \mathrm{kGy}$ dose at $1000 \mathrm{~Gy} / \mathrm{h}$. As observed previously for other parameters, a higher dose was necessary to obtain a similar reduction in modulus of elasticity when radiation was applied at higher dose rates, showing that gamma radiation affects the HDPE more efficiently at lower dose rates.

Despite the fact that irradiation was carried out in the presence of air, the improvement in HDPE mechanical strength properties for certain conditions shows the predominance of cross-linking over oxidative degradation. A probable reason for these results could be sample thickness. With a thickness of nearly $12.5 \mathrm{~mm}$, the samples seem thick enough to prevent a significant part of the material from contact with oxygen. McKellop (1996) mentions a maximum oxidation at a depth of 0.5 to $2 \mathrm{~mm}$. These results are supported by Premnath et al. (1999) who suggest a maximum thickness of $1.6 \mathrm{~mm}$ as a way of assuring the complete oxygenation of irradiated samples. In addition to the oxidation near the sample surface caused by diffusion processes, some oxidation can also occur due to the dissolved oxygen in the sample core. 


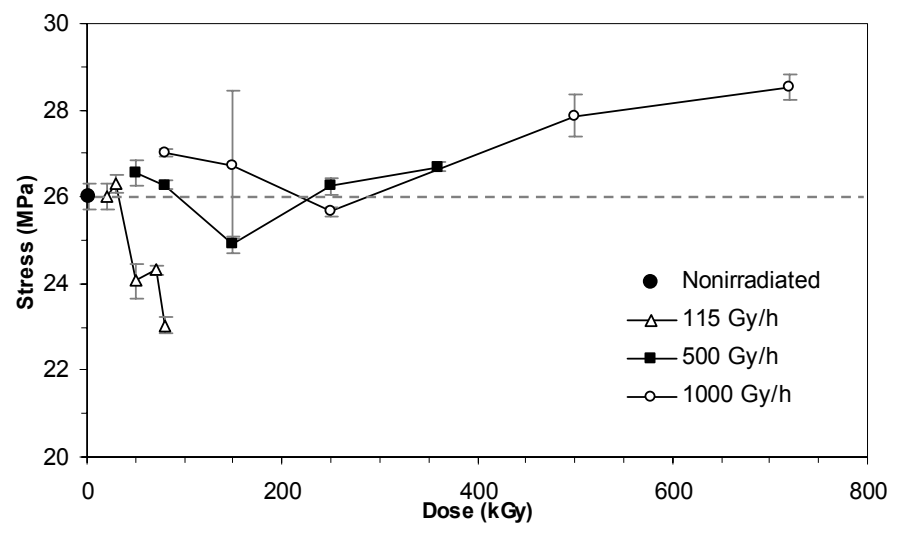

Figure 4: Yield stress of irradiated samples from tensile tests as a function of dose and dose rate. Error bars indicate the $95 \%$ confidence interval.

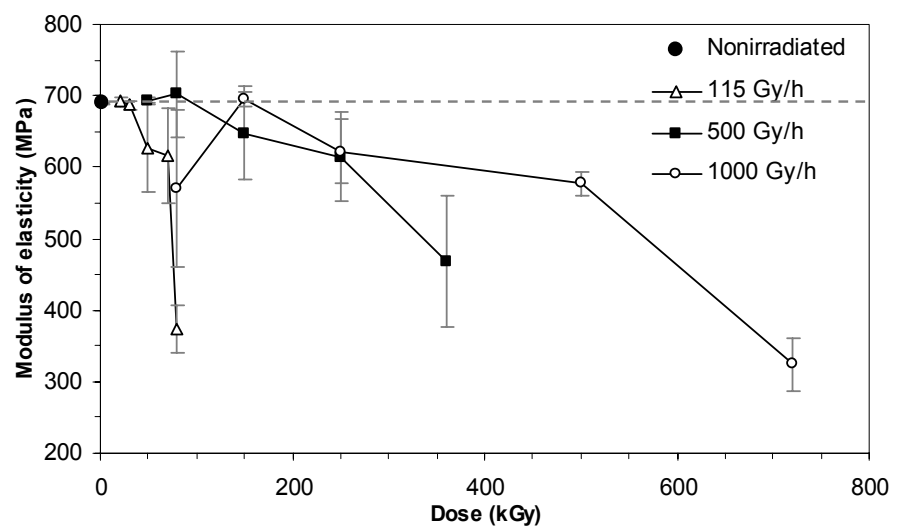

Figure 5: Modulus of elasticity of irradiated samples from tensile tests as a function of dose and dose rate. Error bars indicate the $95 \%$ confidence interval.

The difficulties experienced in analyzing trends in many of the measured parameters (for instance, yield stress and modulus of elasticity) can be associated with many factors. Firstly, there are experimental limitations and uncertainties related to the obtainment of the stress-strain curves and to the evaluation of the mechanical properties. Another possible factor is the nature of many reactions occurring simultaneously during irradiation that can produce opposite effects. Moreover, the nonhomogeneity of these effects across the sample and the fact that mechanical tests measure the macroscopic average of these localized effects also play an important role.

\section{CONCLUSIONS}

Analysis of the changes in the mechanical properties of the HDPE submitted to gamma irradiation shows that (i) the $5 \%$ offset yield stress and yield stress for the compression tests increased as absorbed dose increased and this effect was more pronounced at lower dose rates; (ii) most of the modulus of elasticity values for the compression tests were higher than those for the nonirradiated samples, although tendencies were not well identified; (iii) for the lowest dose rate, yield stress for the tensile tests decreased with an increase in dose, but for higher dose rates, this parameter began to increase; and (iv) the modulus of elasticity for the tensile tests decreased over all dose and dose rate intervals and this effect was more pronounced at lower dose rates.

It is important to observe that the experimental framework used in this work was designed to allow a comparative study of the mechanical strength properties of nonirradiated and irradiated samples of a specific HDPE material. Thus, the validity of the data and conclusions obtained are limited by the assumptions and material used. In order to produce more general data, it is desirable to make use of 
other complementary tests to better characterize the changes in the microstructure of the material due to the application of gamma radiation.

Considering the experimental data from a comparative perspective, the results show an improvement in HDPE mechanical strength properties as dose increases, indicating the predominance of cross-linking over oxidative degradation, despite the irradiation in air, which would theoretically ensure oxygen availability across the sample. These results indicate that sample thickness could be a very important parameter for the design of an irradiation test and should represent the real dimensions of the polymeric component to be submitted to radiation. The results also show that lower doses are necessary to obtain a similar change in mechanical strength parameters when radiation is applied at lower dose rates, showing that gamma radiation affects the HDPE in a more efficient way at lower dose rates.

\section{ACKNOWLEDGEMENTS}

This work was sponsored by $\mathrm{CNPq}$ and FAPEMIG. The authors would like to thank the Laboratório de Irradiação Gama/CDTN and Laboratório de Ensaios Mecânicos/CDTN staff and Professors Dr. Rosario Bretas and Dr. Elias Hage Jr., $\mathrm{DEMa} / \mathrm{UFSCar}$, for the discussions and technical support during the development of this work.

\section{REFERENCES}

ASTM, Standard Test Method for Compressive Properties of Rigid Plastics. ASTM D 695-91, American Society for Testing and Materials (1991a).

ASTM, Standard Test Method for Tensile Properties of Plastics. ASTM D 638-91, American Society for Testing and Materials (1991b).

CEI/IEC, Guide for Determining the Effects of Ionizing Radiation on Insulating Materials. CEI/IEC 544-2, International Electrotechnical Commission (1991).

Martins, A.G., Suarez, J.C.M., Mano, E.B., Produtos Poliolefínicos Reciclados com Desempenho Superior aos Materiais Virgens Correspondentes, Polímeros, 9, 27-32 (1999).

McKellop, H.A., Does Gamma Radiation Speed or Slow Wear?, Bulletin, The American Academy of Orthopedic Surgeons, 44 (1996).

Premnath, V., Bellare, A., Merrill, E.W., Jasty, M., Harris, W.H., Molecular Rearrangements in Ultra High Molecular Weight Polyethylene after Irradiation and Long-term Storage in Air, Polymer, 40, 2215-2229 (1999).

Singh, A., Irradiation of Polyethylene: Some Aspects of Cross-linking and Oxidative Degradation, Radiat. Phys. Chem., 56, 375-380 (1999).

Wündrich, K., A Review of Radiation Resistance for Plastic and Elastomeric Materials, Radiat. Phys. Chem., 24, 503-510 (1985). 